\title{
Teachers' Perceptions about the Role of English in Students' Assessment and Current Practices in Public Sector Higher Education Institutions in Gilgit, Pakistan
}

\author{
Kamal Ud Din ${ }^{1}$ \\ ${ }^{1}$ Faculty in School of Education, Karakoram International University Gilgit-Baltistan, Pakistan. \\ Correspondence:Kamal Ud Din, Faculty in School of Education, Karakoram International University Gilgit-Baltistan, \\ Pakistan.
}

Received:March 17, 2015

doi:10.11114/ijsss.v3i3.770
Accepted: March31, 2015

Available online: April 17, 2015

URL: http://dx.doi.org/10.11114/ijsss.v3i3.770

\begin{abstract}
This study is an attempt to explore different contextual issues related to the use of English language especially as second language when assessing student's learning in different subject areas. The study focused on exploring teachers' perceptions about the role of English language in assessment and their practices related to English language proficiency of the learners, in social science subjects at Higher Education level. Based on criteria, twenty faculty members were interviewed. Document analysis was also key source of data collection. Data were analyzed qualitatively through descriptive thematic approach.

Findings show that the language remains an issue even at First Degree (graduation level). Teachers expect from students that they should not have language related deficiencies. Teachers' expectations from the students in terms of their proficiency in English language were not being met. Few faculty members were viewing no role of English language in the subject they taught because of the nature of the subject they teach. Majority deducted marks (the deduction of marking varied from faculty to faculty) for grammatical mistakes and other deficiencies of students in their speaking and writings. They handled this issue according to their individual approach and understandings. The faculty who thought it impossible that English can be replaced by Urdu at graduation level. It can be recommended that there should be a common, uniform policy about the medium of instruction across the system. It could be a good start if such policies are designed and implemented at institutional level first. Such policies can then be developed for larger than institutional level.
\end{abstract}

Keywords: assessment, conceptual learning, language integrated learning, concept building

\section{Introduction}

In Pakistan, higher education starts after the completion of grade 12 or after higher secondary level, carried out in universities, colleges and other such institutions. (Saeed 2007).

Pakistan has a multilingual society which comprises of five provinces, including Gilgit-Baltistan. Gilgit-Baltistan, the context of this study, is a newly created province. Though it is not constitutionally the part of Pakistan but has been given the status of province for administrative purposes.

The higher education curriculum in Pakistan is the function of respective departments of the universities or colleges. The title of courses and broader framework is usually discussed in the faculty, and then each teacher plans his/her own way to impart instruction in the classroom, however the role of HEC is fixing minimum standards for each degree program in terms of minimum credit hours, nature and weightage of core and other courses and mode of assessment (ibid, p.47).

Before the independence of Pakistan, the education system of India (combined name Pakistan and Baharat) was run by British government which used English as a medium of instruction. Thus after independence English as a medium of instruction has become the part of Pakistani education system as a legacy of British rule. Since Urdu is national language of Pakistan due to the fact that Urdu is considered to be the representative of its culture, therefore different governments have formed committees to make necessary arrangements for replacing English with Urdu. Due to many reasons these arrangement have never been successful. So English continues to be the medium of instruction as well as 
official language creating a controversy among different faction of the society. Sira (2011) has identified three parallel systems of education, as a result of the controversy: they are English Medium, Urdu Medium and Deeni Madarsas. Until and unless there is a clear policy by the government there cannot be an easy way to overcome the controversy. Khursheed (1987) expresses his concern saying that the issue of the medium of instruction in Pakistan is not yet resolved. There are decisions made without proper purposeful and thoughtful discussions in the parliament. One of the many other reasons of indecisiveness in policy making is that the political elite of Pakistan has special interest in English language as it is a source of their power (Rehman 1997). One more recent study by Gulzar (2010) has also found the increasing use of English language in Pakistani education system; however, from his finding we cannot safely say that the controversy is over due to the fact that English is increasingly attracting the attention of the people. For the time being it may be subsided or suppressed. English language is the medium of instruction in most of the institutions of higher education (with classes at graduation level) in Pakistan (Sabiha, n.d). Dearden J.(2014) has reported that among 44 countries including Pakistan, use English as a medium of instruction in their institutions. They use English language in $90 \%$ of their higher education institution.

A country wide study by Sabiha (n.d) has revealed that $65 \%$ of students from private institutions of higher education reported that they are taught in English medium whereas $40 \%$ students from public sector higher education reported English as their medium of instruction. The research was conducted on (2450 as sample size) 30 different degree colleges of Pakistan and 5 different universities from capital cities. This finding indicates that private institutions have higher frequency of using English medium in their institutions than the institution in public sector.

English language being a second (sometimes third or fourth in terms of the mother tongue of the learner's language has implications for the whole academic process (Rehman 1997). Assessment as one the important component of this process becomes a complex phenomenon due to the use of English as a Second language. While the role of English language is recognized in assessment, however what perceptions teachers hold and how they influence the assessment of the students is unknown. There is a vague idea about the role of English language in the assessment. Thus the research study aimed to explore the perceptions and practices of teachers at HE level with respect to the language in terms of what role it plays in the entire process of assessment of content knowledge of the students.

\section{Review of Relevant Literature}

In this literature review section I have tried to cover background and context of using English language as a medium of instruction in Pakistan, its controversial role and its influences in the education system overall and its influence in academics lives specifically. I feel important to mention that there is enough information about how to teach English or assessment of English language learning as linguistic subject but there is lack of literature on the role of English language in the process of assessment in conceptual learning in Pakistani context especially in public sector at tertiary level. This study has been carried out with the expectation to fill this gap to some extent.

\subsection{English Language as the Medium of Instruction in Pakistan}

Though Urdu is the national language of Pakistan but English has the central role in the education system of Pakistan. Why is it so? There are many reasons counted by the researchers and scholars. Shamim (n.d) States one of the reasons which is the prevailing perceptions about English language that is English is considered as a 'world language' for economic and personal development and thought to be a major driving force for the younger generation's desire to learn English in Pakistan.

Rehman (1997) also considers one more reason of using of English language as the medium of instruction as the legacy of old masters because the English people had been ruling in India during their colonization in the past.

Khursheed (1987) expresses his concern saying that the issue of the medium of instruction in Pakistan is being dealt with indecisiveness by the ruling political parties. Some people seem to argue that the required material/content is not available in Urdu that's why it's hard to take a categorical decision.

As has been mentioned earlier that majority of the researchers agree on prevailing controversy regarding English language as a medium of instruction in Pakistan. Sira (2011) mentions as "The medium of instruction is a controversial issue at all levels, especially in the society like Pakistan in which various systems of education are followed."(p. 66).

Aleem (2003) is of the view that the quality of education is the factor that correlates with the difficulties or controversies in the medium of instruction.

Shamim (n.d) however has shown her concern regarding the lack of systematic analysis, debates about the use of English language. She mentioned that at individual and national level there is a desire for development which generally is associated with the learning of English language. Systematic analysis will tell us whether such expectations are valid.

The education system of Pakistan in general and the context of this research in particular involve a great diversity of 
students who come from multiple linguistic background and a mixed up education systems; some have background from Urdu Medium public sector schools where Urdu is medium of instruction and some come from Private schools and Colleges where the medium of instruction is English.

How assessment process is affected by the medium of instruction is an important question. Since assessment process is an integral part of the whole teaching and learning process so it is logically understood that the medium of instruction has to become the medium of assessment as well. However, we need to be careful about the use of such logic because assessment, being an important part of the education system as whole, and specifically being an integral part of teaching and learning process, is also affected by the socio-cultural conditions. Usually, what is expected is whatever language will be in use as a medium of instruction; assessment process will also be conducted in the same medium or the same social context.

As it has been already discussed that Dearden J.(2014) and Gulzar (2010) have indicated increasing use of English as a medium of instruction. According to their findings Pakistan and other countries use English language in $90 \%$ of their higher education institutions. This is a more recently conducted survey that indicates the increasing use of English language not only in the world but also in Pakistan. The increasing use of English suggests the importance of developing criteria about the use of English language in assessment processes.

\subsection{Status of Student's English Language proficiency at Graduation Level in Pakistan}

Language learning involves learning basic communication skills in any language. Such communication skills can be called as basic literacy skills as well. A course on how to teach literacy skill for B.Ed students has been developed by the curriculum developers at HEC in Pakistan. The base of justification for such a course has been made with the reference of National Education Assessment Survey (2006) report, which finds that in Pakistan the school going children are not learning to read properly, even though they go to schools. In Grade 4, 10\% of students achieved $75 \%$ of the items on understanding, interpretation, in the area of language and vocabulary, $0 \%$ of students were able to correctly answer $75 \%$ of the items. Over all less than $40 \%$ of students were able to correctly answer $25 \%$ of the items.

Though the aforementioned survey is related to early education, however has impacts on the higher education because if the basic education is poor then we cannot expect the higher levels to be well in terms of quality in all respects.

Sabiha (n.d) has found that the faculty and students at graduation level face challenges due to their poor language ability. Their performance is negatively affected. Where students face problems in their studies due to English language there the faculty also neglects this factor. Nazia and Hasina (2011) studied assessment criteria in one of the public sector universities. Their analysis suggests that the faculty/participants did not mention about linguistic elements specifically.

The deficiency in language may cause to hamper to communicate their understanding. As Richard et.al (2004) has also mentioned personal communication of teachers with students as an important way to assess their language ability. In such a situation there seems a challenge for teachers to face problems related with language that hamper learning.

\subsection{Integrated Assessment of Literary Skills with the Conceptual Understanding}

As mentioned in the previous section that the problems in concept building are related with language deficiency. In this regard, literature suggests some approaches and techniques that are already in use. Among those techniques code switching and the content and language integrated learning, are worth mentioning here:

- Content and Language Integrated Learning

Nowak (2011) defines CLIL as a pedagogical approach which has a dual (integrated) role through which learning of the subject matter and learning of the second language both take place at the same time.

This is also an emerging concept of Content and Language Integrated learning (CLIL). It is an approach to teaching both English language and concepts at the same time. It is bilingual method of teaching unlike the monolingual approach. The monolingual approach does not allow for any other than the target language in which the teaching and learning is supposed to take place in classrooms.

There are no two opinions on the role any language plays in attainment of knowledge because language is not only a medium which is used to get knowledge but also itself a learning process (William and Miller 2003).

Charles (1997) discussing the linguaistic accuracy in language learning states: "Lingusitic accuracy is an interesting, relevant consturct for research in three areas of second language acquistion, writing assessment and L2 writing pedagogy"'(p 102).

Keeping in view the deep relationship of knwolege acquistion and the langauge through wich knwoglge is acuired one of the techniques is the integration of assessment of both language as well as knowledge learning especially in the areas of social science subjects . 
Dalton (2011) called it a "duel focused approach". The writer indicates the concerns of educators and parents about the language being used in schools for teaching children.

Jarmila and Mari (2011) suggest that teachers who use this approach need to have a good command of the target language and can resort to the learner's mother tongue with care.

Problems are to be handled through useful techniques and strategies as suggested by Jarami and Mari (2011) that Code switching and (CLIL) for initial stages in learning but we feel that it can also be recommended for the teachers at college and University levels if the situation demands so. The same is logically justified to apply for any assessment criteria as well.

\section{- Code Switching in Formative Assessment stages}

Code switching and "judicious use" of English as second language is another widely-in-use technique used not only in teaching English but also used for teaching other subjects of social science. It helps in addressing the problems related to language while learning concepts. It is about the use of both mother tongue and Second language as per need. Gulzar (2010) recorded interview of teachers that showed that the teachers' purpose-oriented codes- witching is acceptable in situations that demand of doing so. Michael L. (2009) indicated limits of code-switching saying that it is useful in discussions but offers no help for learners in writing tasks and assignments. Thus code switching can be a need based approach for teachers where they think the mother tongue or the first language is inevitable to explain some certain concepts and ideas. In such cases it can be used in the process of assessment for instance in Pakistani context, (as we have seen exam papers) the external examination boards allow students to attempt paper in either of the languages, Urdu or English.

\section{Methodology}

The main objective of the study was to identify and explore the perceptions of the actual practitioners who were involved in assessing students in their respective subject areas. The objectives can be achieved only when they go along with the compatible procedures.

The nature of this study was qualitative in many respects:

- It was qualitative because it aimed to study perceptions and practices of the participants with the perspective of discovering different dimensions of the phenomenon of language in the process of students' assessment in social science subjects.

- It aimed to find out the answers to the questions related to the use of English as second language in the process of assessment at graduation level.

- It was qualitative because most of the reporting involves descriptions of the perceptions and practices in a natural setting, and where the researcher has played a role as a data generator (Marshall \& Rossman, 1999; Merriam, 1998; Rossman \& Rallis, 1998).

The above discussion provides a convincing perspective and rationale for the use of qualitative approach of analysis and interpretation. It was qualitative so that the genuineness of the interpretation and analysis as per observation could be maintained.

\subsection{Sampling, Data Collection and Analysis Procedures}

The body of literature on qualitative studies also shows that purposive sampling is commonly used in qualitative studies. Since this particular study is an exploratory qualitative study rooted in the understanding of the perceptions about the role of English language on students' assessment in Higher Education institutions in Gilgit, Pakistan. The subject areas selected in which assessment is carried out have a specific purpose which is that the subjects are social science subjects which are not intended to develop English language skills but to teach concepts, however assessment is done through the use of English, that too as a second language.

We selected institutions located in the Gilgit city. The rationale behind selection of institutions in Gilgit city is that the city is the central hub of the entire region of Gilgit-Baltistan. Given the vast population of the city, most of the colleges including KIU, which is the only university in the region, are located in the city. Institutions for this study have been selected on the basis of the following criteria.

a) Higher Education institutions located in Gilgit, Pakistan

b) Institutions that offer degree level programs;

c) Inclusions of both institutions for boys and girls

In order to select the individual research participants which were twenty in number, the following criteria were used. 
a. Faculty members who teach Social Science Subjects. As social science is a broad area so from social science only those subjects are included in the studies which are being most commonly offered in the institutions under study. These include Education, Economics, Psychology and Sociology.

b. Those faculty members who are permanent or full time employees. Inclusion of research participants from both the gender has been made.

As this study was a social science research therefore an appropriate tool is Interview. Interviews are structured and unstructured. For this study Semi structured interviews have been used due to its flexibility for the adjustment of related but un-preplanned questions. In addition, document analysis and review were also source of data collection.

The main method of analysis was thematic analysis which considered being within the parameters of qualitative approach to any study. Different themes that could be generated from the data had been described, interpreted and discussed.

\section{Major Findings Related to Perceptions}

There were two main themes identified: the perceptions and the practices of the research participants. In the following section different findings have been presented under the main headings of the themes just mentioned.

\subsection{English Language is Considered to be an Unavoidable Necessity}

It was found that all the research participants pointed out the importance of English language as medium of instruction. The most frequently shared points regarding the importance of English language were that English needs to be continued as medium of instruction because of it being the source of communication with international community and the source of modern knowledge. They seemed to be aware of the status given to English language as well as approving and willing to use it mostly during their lectures in class. One of participants mentioned which was also pointed out by fifteen out of twenty participants:

English language as medium of instruction should be maintained in our education system especially in professional degrees whereby graduates have to join different national and international organization. Without having English proficiency one cannot compete in the modern world. (Respondent five. interview: June $7^{\text {th }}$ 2013)

Similarly, some of the research participants shared the importance of language during the assessment. They mentioned that no matter how clear in concepts the students are, without good English they cannot express their ideas. It is clear that those who are good in English as well as in concepts exceed those who lack in any of these.

\subsection{Absence of Uniformity with Respect to Medium of Instruction}

The research participants indicated some factors and their concern about determining one uniform policy regarding language. They thought medium of instruction, whatever it is (preferably English) is a policy level issue. Their main concern was the uniformity in the whole system in terms of medium of instruction. For them it was of secondary importance whether the medium is English or Urdu or any other language, they thought that it should be same across the system and the level. One of the participants said "the medium should be uniform throughout the institutions. I.e. whether it is Urdu or English, it should be kept same from school to university level" (Respondent thirteen, Interview on 28/08/13).

\subsection{Faculty Expectations from the Students with Regard to Their Language Related Problems}

During the interviews questions were asked about the research participant's expectations from their students with regard to their language proficiency as well as the existing conditions, particularly at the level they were teaching.

The analysis of the overall responses revealed that, around $90 \%$ participants had high expectations from the students' regarding their language proficiency. They said they expect that their students should be fluent in speaking, writing which must not contain any grammatical mistakes.

It is in my observation that majority of my students who have deficiency because of their poor academic background. At this level they are expected that if they concentrate on their mistakes in English and try to avoid gradually they can improve. (Respondent fourteen, Interview:16-06-13)

Nevertheless almost all of the participants expressed their concerns that in reality, their students never met the expectations. They shared that this was an ideal situation that the students at graduation level do have issues in terms of language deficiency because the student have been learning English as a compulsory subject from beginning of their early education 


\subsection{The Nature of Subject as a Determining Factor for Considering Students' English Language Ability in Assessment}

Some of the research participants mentioned that, if their students did not meet any expectation in terms of language ability it made no difference. They were giving the reason that the subjects that are being taught are supposed to measure some other ability than the language (concept understanding) of students not language abilities. Around $15 \%$ of them did not consider the language as a hurdle in this regard. One of the research participants, for example, said:

As far as students' writing is visible and understandable at this level it's ok for me because that's what I expect from them. It is not necessary that they are expert in language and know grammar well. Grammatical mistakes do not matter in communicating ideas. The course I teach is not supposed to make them expert in language. (Respondent Fifteen, Interview: 12/07/13)

The statement of the research participant can be prone to being misjudged apparently. What is interesting, is the remarks of this respondent that seem to be suggesting, though indirectly, that 'writing is visible and understand-able'. The point of argument here is that "understandable answer" has the element of language ability of students because of this ability their answer can be understandable. It should be kept in mind that the research participants were not English teachers while they taught other than English subjects. The nature of content matter of their subject was the main reason of not giving importance to the English language of the students. However none of them denied the importance of language proficiency of their students.

\subsection{Improving Quality of Education in Schools May Minimize the Language Deficiencies in Students at HE Level}

The research participants were also asked question which meant to draw suggestions respecting to deal with the issue. In reply to such questions they mentioned the reasons behind the problem which, according to them was the poor language background of the students and undetermined nature of policies with regard to the standardization in different level of education. Standardization is not clear in the education system in terms students' performance at different levels as well as in terms of qualified teachers, facilities, merit system and monitoring and evaluation.

It was clear from the views of the participants in HE institutions, English language as medium of instruction is in place, yet there is a dire need of a defined policy and procedures with respect to the role of English in assessment. The flaw in fact lies in the entire education system at all levels. One respondent said. "There are many reasons but I think three factors are the most important: lack of qualified teachers, poor examination system, and shyness among students" (Respondent One and Two, Interview: 20/06/13).

Shyness of the students in the context of sharing ideas again seems to be due to poor education system, however this problems has its roots in social set up. This aspect seems as pressing one because as one faculty observed most often that the student do not speak in class due to fear of peers' teasing on their mistakes. Such behaviors in society become an invisible but significantly influential in the process of learning. The learning of language actually is developed in social and informal settings.

As discussed in the above section, majority of the participants thought that change of medium of instruction is not possible in the current scenario, at least in near future. Few put forward the idea that instead of changing the medium of instruction there is a need to improve the quality of teaching at all levels. If we are able to do so then we will not have the issue of medium of instruction. It surfaced from the data that in our education system it is not just the English language but, there is no satisfactory performance in other subjects like mathematics and science subjects.

\subsection{Environment of an Institution Plays a Pivotal Role in the Students' Language Proficiency}

Majority of the research participants agreed on that the environment and culture of institutions plays a pivotal role in the language ability of the students. One research participant shared his experience that when he was abroad for studies, his English speaking skill was very fluent but now due to disuse or minimum use he feels hindrance while speaking himself. It was due to the fact, as he said that he had been teaching to students who were unable to communicate in English or able to understand when used English in lectures or discussion. He emphasized that the Environment is necessary where teachers and students could be bound to speak English, otherwise having mother tongue as an easy available option everybody is inclined to use that language

The participants stressed on the use of productive skills (speaking and writing). They thought in academic setting these two skills are more in use. The level of students also suggests that they must try to use their knowledge of language which they have got in their previous grades. Other research participants mentioned that the students had poor learning of language at the previous classes where they have been stuffed with knowledge of grammar and vocabulary but the student had not given enough time to practice. One respondent suggested to students for improving their writing and speaking skills, and said "They should attend Standard English courses, watch English movies, read English books etc."(Respondent Two, interview: $20^{\text {th }}$ June 2013.) This point was also shared by respondent seven, seventeen and twenty as well. 
Table 1. Summary of the Common Perceptions of the Use of English Language

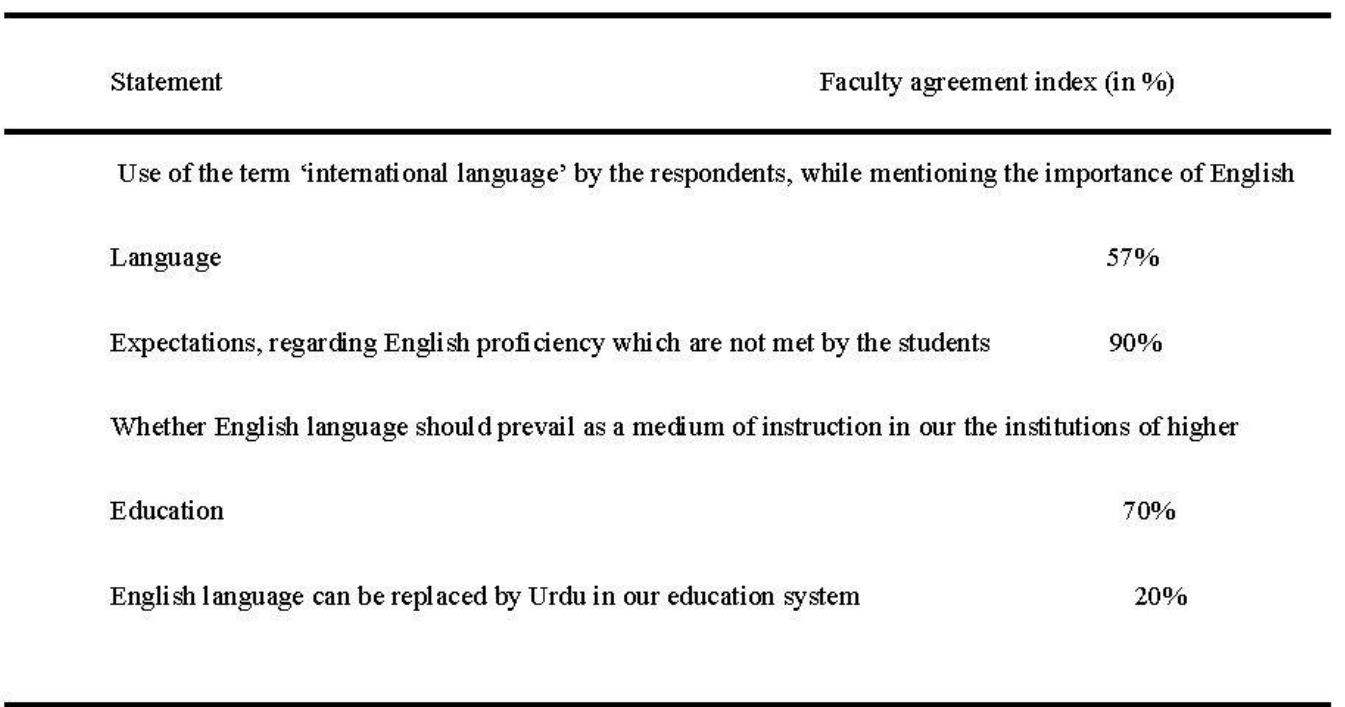

Table 1 shows an overall picture on some major perceptions that came to the surface during the interview discussions with the research participants. The percentage of research participants who shared common perceptions will help to have quick view of the nature of perceptions frequently occur. It shows what factors are considered for English language to be important, what expectations from students at graduation level and perceptions on the controversy of medium of instruction in the education system of Pakistan. Therefore, after presenting findings with respect to the research participants' perceptions about the role of English in the assessment process and the reasons behind those perceptions, we would now discuss in the following section findings regarding assessment practices in the context of language ability in content areas.

\section{Major Findings on Practices in Assessment}

This section explains the actual practices of the research participants with respect to the language ability in the assessment processes. The practices tell about the approaches and strategies of the research participants about the use of English language in assessment of students at graduation level in the area of content knowledge learning. Few main practices were identified such as the use of both the first language (Urdu) and the second language during assessment when needed, individual criteria for assessment of students, cutting down marks for language related mistakes in writings of the students, providing only feedback and guiding students for taking responsibilities for their language development without considering much about their language mistakes.

\subsection{Use of First Language (FL) on Need Basis}

A research participant indicated: "unfortunately I have to use both the language as I have different students who have different levels of ability". On counter question whether did they think in case of using Urdu their students would do well. She replied "at least they can say few words. In English, majority is unable to say even few words. They either remain silent or feel shy and get afraid of committing mistakes if they speak." (Respondent Seven, Interview: 20/08/13)

Other participants also suggested that ideally they should or want to use 100 percent English language during lectures but practically they are unable to do so because the students feel bored because students do not understand properly. Here there was a dissonance between what was thought to be ideal and what was being actually practiced or implemented. However, few participants were also of the opinion that since the objective the subject they teach was not developing language skills, so they use any language they feel appropriate in order to communicate the concept. This was what they expect from the students in oral presentations which are commonly used in classes to assess students' performance.

\subsection{Grading is Affected by Language Deficiencies of the Students}

In the previous theme it came to surface how importance was given to English language in assessment irrespective of the nature of subject. It also came to be known that the faculty expectations from the students were not being met by the students in terms of their language proficiency.

In response to a question regarding how they assess if students have a poor sentence structure or poor vocabulary in their assignment or papers the respondent replied: "I check for concepts however a good English impresses me too, certainly full marks or high marks achievers are well in both concepts and language ability." For clarity of response 
when they were asked to tell in quantitative terms specifically about marking they said. "I deduct 3 to 4 out of 10 marks if the language is too bad however it depends on overall readability of the text of the students as well." (Respondent Two, Interview: 20/06/13)

\subsection{Providing Feedback on Both Language and Concepts}

The following are some of the examples how the research participants give feedback to their students during assessment. "I have to provide feedback mostly in the area of concept making not in language, few times I have to consider if I see the condition of English language too bad.", said one of the research participants (Respondent One, Interview: 24/06/13)

Another participant highlighted one important aspect of his assessment, and said that he had most of the time to provide feedback in language area rather than conceptual learning due to the reason that most of the students, according to him, are not able even to write few sentences free of language related mistakes. He further added that overlooking their mistakes and teaching concepts becomes a meaningless activity. This research participant was vigilant in providing feedback because they seemed to know their students language ability well enough to detect (while reading their assignments, and papers etc., whether they have used their own language or they have reproduced what they have rot from notes or books.

\subsection{Guiding Students to Realize Their Responsibilities}

The research participants who told that they simply avoid giving any feedback on linguistic mistakes if the concepts are readable; they said they only guide the students about their language but not cut their marks for grammatical mistakes or any other sentence structure. To them any clue to show that a student has the idea of that concept was considered to be sufficient. They seemed to think only to make the students realize, if time allows, of what they lack in their academics and guide them how to improve.

They thought the responsibility rests on the shoulder of the students to improve their confidence and language ability if they lack. "We don't have time to teach them grammar and how to write because we have to cover up the courses in due time". (Respondent seventeen, interview: 18 July, 2013).

The overall analysis of such practice revealed that language was not considered as part of the criterion developed for assessing students that affected their grading. This was also in practice by few of the research participants under study.

\subsection{Nature of Criteria Varies at Individual Level for Assessing Students}

It was found that there was not a fixed criterion with respect to the language in the assessment processes. Participants mentioned that they did not include the component of language in their individual criteria of assessment. As one respondent responded as "I think it would be a wrong step. It is not possible. The students will suffer inferiority complex."(Respondent Six, Interview $9^{\text {th }}$ July 2013)

The reason they shared that as the purpose of the course is not to develop language learning. Moreover few discussed if they do so they have to face reactions from the students.

The respondent further stated that once he had asked from his students in a session whether they would object for criteria for deducting their marks due to their poor language in written from, only 3 out of 30 students seemed to agree with such marks for language deficiency.

Table 2. Quantitative Analysis of the Nature of Common Practices

\begin{tabular}{lc}
\hline Statement & Faculty agreement index (in \%) \\
\hline Use 100 percent English language in faculty lectures & $05 \%$ \\
Use of mix up (Urdu and English) percent English language in their lectures & $90 \%$ \\
Engli sh language is considered during assessment process & $70 \%$ \\
Objections received from the students on assessing their language ability & $60 \%$ \\
Only feed back to improve language is provided without considering the language ability in assessment & $30 \%$ \\
\end{tabular}


Table 2 shows that most of the research participants used English as well as Urdu in their lectures and interactions with the students. Only 05 percent used 100 percent English language. However local languages have never been used for academic discourse, though they use local languages (other than Urdu) in informal interactions such as meeting at the canteen or at corridors talks intended for some other information than academics like greetings and asking about a relative etc. Urdu language is by default a formal language, though curriculum is in English and most interestingly the exams are conducted in English language.

\section{Analysis of Documents-A Reflection of the Perceptions and Practices}

Question papers and assignment already assessed by the faculty have been a great source of information that helped in knowing the actual practices of the faculty regarding the problem understudy. Few extracts of the students answers have been taken from the midterm papers for these papers are shown to the candidates and thus work as feedback. Here the strategy adopted is to review the checked papers and identify the nature of underlined words, sentences and any other kind of indication of feedback provided by the teachers.

The analysis of these papers showed $3 / 5$ teachers had just put a check mark or cross on the pages and allocated marks. Those who indicated showed that they could not read the papers easily due to improper language used in the paper. A teacher also shared his observations that in a class discussion with students 25 out 30 students said that their papers or assignments seemed not properly read by the teachers. The following extracts are taken from students papers which have been typed on 'as it is' basis from the paper along the marks granted by the teacher. It will not only show the language of the students at HE level but also the practices of teachers towards assessment of the students. The findings of the documents were depicting that almost all of the graduates had language problem in their writings. To avoid the length of the article only two such extracts are presented in the boxes below:

Q. Discuss why we need to study about philosophy?

[Writer (1)1. "Philosophy is the crital science and universal rules. We need study philosophy because we know about the univers, human being, nature and other natural things. if the person study the philosophy they try to understand about this things. For example: the philosopher study about the world, is there are one world or many."(got 2.5/3 marks)]

This answer of the student contains spelling mistakes like the term "critical" has been spelled as "crital". It seems such spelling can be overlooked because it seems in speedy writing it can be expected however ideally it may be considered as linguistic deficiency on the part of the student. One can argue that nowadays computer can help for spelling mistakes so it can be considered as an error which is due to the limitations of test administration. When read the whole answer we see more such spelling mistakes like the term "univers",. This answer also contains grammatical mistakes like 'we need study...' contains a wrong construction but the message is any way clear. In the second last line 'this things' also contains a grammatical mistake. Now when we look at the marks the teacher has deducted only 0.5 marks. It may be inferred that though the grammatical mistakes were there yet the concept was clear which the student wanted to communicate to the teacher. However on the paper these mistakes were underlined by the teacher in red ink.

Q. What is inductive method of philosophy?

[Writer No(1) 2: "inuducative method is specific to general. In this we belie one to whole. if there is a reason. Phylosophy uspetiscuss about the main problem and concouled the main main reason. If a person is mintal upset. They philosophy study what is the inner problem. Not treatmetnted system just observe the person and got the main problem."(got 01/03)marks)]

The above lines are the actual writing of the students, extracted from a midterm paper that suggests the inaccuracy in writing and deficiency in basic grammar.

\section{Conclusion}

The perceptions of teachers about the role English Language as a medium of instruction and assessment along with their current practices of assessing their students was the aim of this study. The main perceptions about the use of English language assessment reveal that the use of English language is still considered to be a controversial issue. Shamim (n.d), Tehseen (2013), Rehman (1997), Khan (2010) also seem to agree that the medium of instruction in Pakistan is a matter of great debate among teachers, educationist and parents. However in the current study it was not as such controversial because majority of the teachers considered the importance of English language as unavoidable necessity and thus suggested for its development as a medium of instruction in future from primary to higher level. The research finding also suggests the teachers seem to give less important to the controversy. Aleem (2013) is also of the view that it is too much that we have been repeatedly discussing this issue in our academic circles. He seems to indicate to move on with the current situation. He seems inclined to suggest the continuation of English as a medium of instruction. 
It was also found that the language and conceptual learning cannot easily be defined and dealt separately. The teachers also felt the poor background of the students as a significant reason for their language deficiency even at higher level. It meant that quality of education was considered to be an important variable which can address the language issue. They thought it was the poor quality of students' background education that causes the student to remain deficient in their English proficiency even though that are taught English as a compulsory course from nursery to graduation. National Educational Policy (2009), with reference to National Education Assessment System (2007), also recognizes that there is significant quality deficit and also confirms the wide spread perception of low quality of education in Pakistan.

Along with finding the practices of the teachers were not of less importance. Their priority was to use English language in their lectures and sessions but they had to rely on Urdu language to make the students understand the concepts they were teaching. Among the practices about assessment all teachers gave weightage to language ability in checking their student's papers and oral discussion that are carried out to assess their understanding. In written feedback teachers consider grammatical mistakes, broken sentences, use of irrelevant and poor vocabulary of students. They encircled them and deducted marks as per their own criteria of assessment. However, there is not any standard, policy or procedures available with respect to the role of language in assessment. The study found that research participants follow their own individual rules and procedures in connection with the role of language in the assessment. It is different to different teachers.

\section{Recommendations}

1) It is recommended to the higher education leadership to design a criterion at the institutional level about how to handle the language issue if it is found in their particular settings. They can take steps for a uniform policy for their faculty. Higher Education Commission may take a leading role in this regard.

2) For teachers this study recommends and suggests the importance of setting criteria at individual level if they do not have collective criteria at their institutional level. Identification of students' individual problems would be an important factor in setting such criteria. Those teachers who used already such criteria, in which language had a place in their assessment, have shown positive responses from the students.

1) The research participants thought that students' earlier language deficiencies in schools continue to create hurdles for them at the HE level. Based on this finding it can be recommended that the HE institutions should work with the schools (because they are the key feeding unites), with respect to the language improvement of the students.

2) The study also recommends that there should be clear policies and procedures in place regarding the role of English language, not only as a medium of instruction but also in the assessment of the students' assessment especially the assessment of conceptual understanding.

3) Educational Researchers are recommended to further investigate the implication of any change in the policy regarding medium of instruction and its political, social and administrative aspects.

\section{References}

Ahmad A. (2013). Global Science: The English Urdu Medium Controversy, 87(964), Karachi, Ibn-e-Ahsan Offset Printing Press.

Angela S.(n.d). Interpretation in Assessment and in Teacher Learning. Research Centre for Languages and Cultures School of Communication, International Studies and Languages, University of South Australia, Magill Campus, Adelaide, Australia

Charlene G. (1997) Measures of Linguistic Accuracy in Second Language Writing Research: Language College Press Amsterdam Avenue, New York, NY

Dennis H., \& Cramer D. (2010) to (Edi: 2nd ) Chapter 21: thematic analysis: Introduction to Research Methods in Psychology. London. Pearson Education

Douglas, N. (2007). Checking For Understanding: Formative Assessment Techniques for Your Classroom, U.S.A., Association for Supervision and Curriculum Development (ASCD) Publications

George, J. W., \& Cowan, J. (1999). A Handbook of Techniques for Formative Evaluation: Mapping theStudent's Learning Experience. London: Taylor \& Francis

Ghulam (2007). Education in Pakistan: The Key Issues, Problems and the New

Challenges. (2007). Journal of Management and Social Science, 3(1), 47-55. Department of Education: University of Karachi, Pakistan.

Government of Pakistan, Ministry of Education, National Educational Policy (2009) 
Government of Pakistan, Ministry of Education, National Education Assessment Survey (2006)

Ground-Smith, S. (2003) Teaching challenges and dilemmas: investigating, assessing and reporting student learning ( 2nd Edition). Nelson Australia Prvt. Limited (Thomson Learning Australia.)

Gulzar, A. M. (2010). Issues of Language(s) Choice and Use: A Pakistani Perspective. Pakistan Journal of Social Sciences, 30(2), 413-424

Khurshid, A. (1987). Hamara Nizam-e- Taleem. Intitute of Policy Studies, Islamabad.

Marshal C., \& Rossman, G. B. (1999). Designing qualitative research: (3rd ed.). London: Sage Publications.

Nazia, K., \& Hasina, M. (2011). Importance of Professional Development at University Level .Unpublished Master thesis submitted to the Karakoram International University Gilgit- Baltistan Gilgit.

Pakistan Gallup Survey Report. (2009). www.gallup-international.com; www.gallup.com.pk

Rehman, T. (1997). The Medium of Instruction Controversy in Pakistan, Journal of Multilingual and Multicultural Development. National Institute of Pakistan Studies, Quaid e Azam University Islamabad, 18(2).

Richard, A. J.,Chappuis J., \& Chappuis, S. (2004). Classroom Assessment for Students. Assessment Training Institute Portland; Oregon.

Rossman, G. B., \& Rallis, S. (1998). Learning in the field: An introduction to qualitative research. Thousand Oaks: Sage Publications.

Sabiha. M (n.d). Language Planning in Higher Education Issues of Access and Equity. The Lahore Journal of Economics, 8(2) Downloaded on 15th April, 2015 from: http://www.lahoreschoolofeconomics.edu.pk

Saeed, M. (December 2007). Education System of Pakistan and the UK: Comparison in Context to Inter-provincial and Inter-countiries reflections. Bulletin of Education and Research, 29(2), 3-57.

Saif. M. M. (2009).Understanding Languistics. Khalid Waheed Malik Famous Products Lahore.

Siddiqui, S. (2010). Rethinking Education in Pakistan: Perceptions, Practices, and Possibilities. Paramount Publishing Enterprise.

Sira, I. (2011). Issue of Medium of Instruction in Pakistan, International Journal of Social Science and Education, 1(1), 66-82.

Shamim, F. (n.d). English as the language for development in Pakistan: Issues, challenges and possible solutions

In-H. Coleman (Ed). Dreams and Realities: Developing Countries and the English Language, 1-20. The British Council.

Teshseen (2013). The Role of Medium of Instruction used in Pakistani Schools. Interdisciplinary journal of Contemporary Research in Business, 4, 609-615. New ports Institute of Communication and Economic, Karachi.

Thomas, A. P. (1993). Classroom Assessment Techniques: A hand book for College Teachers. (Edi: 2nd). California: Jossy-Bass Inc.

William, M., \& Gloria, E. M. (2003). A Handbook of Educational Psychology: John Wiley \& Sons, Inc., Hoboken, New Jersey.

\section{(cc) $\mathrm{Br}$}

This work is licensed under a Creative Commons Attribution 3.0 License. 